Bull. Mater. Sci., Vol. 6, No. 2, May 1984, pp. 317-325. C Printed in India.

\title{
Pyroelectric materials
}

\author{
M R SRINIVASAN \\ Materials Science Group, Tata Institute of Fundamental Research, Bombay 400005 , India \\ Abstract. This paper presents a review of pyroelectric materials. The physics of pyroelectric \\ materials is described. Various pyroelectric materials are compared for their efficiency in the \\ detection of radiation. Current trends in pyroelectric material technology are highlighted.
}

Keywords. Pyroelectricity; ferroelectricity; piezoelectricity.

\section{Introduction}

It has been known for a long time that some crystals exhibit electric polarization when their temperature is changed. This phenomenon is known as pyroelectricity and arises out of the temperature dependence of spontaneous polarization in these crystals. The pyroelectric polarization, however, does not persist for a long time and gets neutralized due to imperfect insulation and the presence of free charges in the crystal. While all the ferroelectric crystals are necessarily pyroelectric, the converse need not be true. A builtin asymmetry in the crystal structure hindering the polarization reversal or a high coercive field exceeding the limit of electrical breakdown might prevent a pyroelectric from being a ferroelectric.

Quantitatively, the pyroelectric effect could be described by the equation

$$
\Delta P_{i}=p_{i} \Delta T,
$$

where $\Delta T$ denotes the change in temperature, $\Delta P_{i}(i=1,2,3)$ are the changes in the components of polarization $P$ in the three-dimensional space and $p_{i}$ are the corresponding pyroelectric coefficients. $p$ is a vector property and by Neuman's principle ought to remain invariant under all the symmetry operations of the crystal (Nye 1962). Hence pyroelectricity can be exhibited only by crystals belonging to the ten polar classes $1,2 \mathrm{~m}, 2 \mathrm{~mm}, 3,3 \mathrm{~m}, 4,4 \mathrm{~mm}, 6$ and $6 \mathrm{~mm}$.

It may be pointed out here that in some crystals polarization may appear under the influence of hydrostatic pressure and this is a special case of piezoelectric effect. Since hydrostatic pressure is a scalar-like temperature this polarization linearly proportional to the hydrostatic pressure can also be tredted on par with pyroelectricity. Thus the piezoelectric effect under hydrostatic pressure can occur only in the above mentioned ten polar classes. In general the piezoelectric effect has the mathematical character of a third rank tensor and is restricted only to 20 non-centrosymmetric classes excluding the class 432 . Thus the symmetry permits all the pyroelectric crystals to be piezoelectric while the converse is not true. Therefore it is possible to imagine two possible contributions to pyroelectricity in the following way. Experimentally to observe pyroelectricity one can heat the crystal and observe the change in polarization. The experiment could be performed in two ways. Either the shape and size of the crystal can 
be kept fixed during the heating or the crystal may be released so that thermal expansion can occur quite freely. Obviously the magnitude of the effect observed in-the two cases will be different. In the first case the crystal is clamped and the observed effect may be regarded as the primary pyroelectricity. In the second case, in addition to the primary effect, there is pyroelectric effect due to the variation of piezoelectricallyinduced polarization with temperature. This is known as the secondary pyroelectricity. The secondary pyroelectricity is found to contribute substantially to the total effect.

Hence for a free crystal the total pyroelectric effect could be written as

$$
(\mathrm{d} P / \mathrm{d} T)_{\sigma, E}=(\mathrm{d} P / \mathrm{d} T)_{S, E}+(\mathrm{d} P / \mathrm{d} S)_{T, E}(\mathrm{~d} S / \mathrm{d} T)_{\sigma, E}
$$

where $\sigma, S$ and $E$ denote the stress, strain and electric field respectively. Equation (1) could be written as

$$
\begin{aligned}
p^{\sigma, E} & =p^{S, E}+(\mathrm{d} P / \mathrm{d} \sigma)_{T, E}(\mathrm{~d} \sigma / \mathrm{d} S)_{T, E}(\mathrm{~d} S / \mathrm{d} T)_{\sigma, E} \\
& =p^{S, E}+\mathrm{d}_{i j k}^{T, E} C_{j k l m}^{T, E} \alpha_{j k}^{\sigma} E
\end{aligned}
$$

where $p^{\sigma, E}$ is the total pyroelectric coefficient; $p^{S, E}$ is the primary pyroelectric coefficient; $\mathrm{d}_{i j k}, C_{j k l m}$ and $\alpha_{j k}$ denote respectively the piezoelectric moduli, elastic compliance coefficients and coefficients of thermal expansion. Clearly the secondary pyroeleciric coefficient is given by the product of $d_{i j k}, C_{j k l m}$ and $\alpha_{j k}$. Though secondary pyroelectricity is due to piezoelectricity, only those piezoelectric crystals which belong to the ten polar classes are permitted by crystal symmetry to exhibit secondary pyroelectricity.

So far we have tacitly assumed that the temperature of the crystal is the same at all points. Uneven heating causes temperature gradients, which by thermal expansion give rise to non-uniform stresses and sirains. Under such conditions it is possible for piezoelectric crystals like $\alpha$-quartz, which does not belong to the ten polar classes, to exhibit secondary pyroelectricity. This secondary pyroelectricity due to non-uniform heating is.called the tertiary pyroelectric effect. The tensorial pyroelectricity refers to the production of quadrupole or higher electric moments on heating.

\section{Theory of pyroelectricity}

In principle, in order to understand pyroelectricity in any material, one has to consider the various mechanisms of the spontaneous polarization (such as ionic, electronic, orientational or surface charge) and study their variation with temperature. The pyroelectric behaviour is fully described by the temperature variation of pyroelectric coefficient. Actually, it is convenient to consider the temperature variation of primary and secondary pyroelectric coefficients separately. The temperature variation of secondary pyroelectric coefficient is governed by those of piezoelectric moduli, elastic compliance constants and thermal expansion coefficients. Both piezoelectric moduli and elastic compliance constants are not strong functions of temperature, in those crystals which do not undergo any phase transition. Hence the temperature variation of secondary pyroelectric coefficient is akin to those of thermal expansion coefficients. Conceptually, the origin of primary pyroelectric effect and its variation with temperature is more difficult to visualise and has invoked considerable discussion in the literature. 
The lattice dynamical theory of primary pyroelectricity for the case of ionic crystals was first formulated by Max Born in the year 1945 (Born 1945). In this paper, Born had indicated that primary pyroelectric coefficient would be proportional to $T$, though in his later treatise on latrice dynamics he predicted the $T^{3}$ law for the pyroelectric coefficient (Born and Huang 1954). Recently Szigeti has brought out clearly many salient features of the theory, especially the role of mechanical and electrical anharmonicity in primary pyroelectricity which in fact was overlooked by Born (Szigeti 1975, 1976).

In the case of ionic crystals, there are two important mechanisms of polarization. One being responsible for absorption in the infrared i.e. the lattice or ionic polarization and the other in the ultraviolet i.e. the electronic polarization. In the very simplest and crude model known as the rigid ion model, the electron cloud around the ion is assumed to be rigid and consequently there is no contribution from electronic polarization. For such a model, the total dipole moment of the crystal is given by

$$
M=\sum_{a} \alpha_{u} Q_{a}
$$

where $Q_{a}$ are the active normal coordinates i.e. those which produce uniform polarization in the direction of $M . \alpha_{a}$ are suitable normalizing constants.

However, in reality the electrons are deformed during the lattice vibrations as they experience short range forces and also the dipolar field due to ions. The electron deformation is not just lineariy proportional to lattice displacements but involves higher terms as well. Hence when one takes into consideration the electronic polarization also, the dipolemoment of the crystal is given by

$$
M=\sum_{a} \alpha_{a} Q_{a}+\sum_{j j} \beta_{j j^{\prime}} Q_{j} Q_{j^{\prime}}+
$$

An importunt point to note is that $\alpha_{a}$ includes both the effects due to lattice displacements and also the first order effects due to electron deformation. The above expression for the dipolemoment clearly implies the presence of electrical anharmonicity in the crystal.

For the case of harmonic crystal, the potential energy is proportional to the square of the normal coordinates. In reality crystals are not harmonic and the mechanical anharmonicity has to be taken into account. For such a crystal the potential energy involves the cubic and high:r powers of the normal coordinates

$$
W=\frac{1}{2} \sum_{j} \omega_{j}^{2} Q_{j}^{2}+\sum_{j j^{\prime} j^{\prime \prime}} b_{j j^{\prime} j^{\prime \prime}} Q_{j} Q_{j^{\prime}} Q_{j^{\prime \prime}}+
$$

The primary pyroelectric coefficients $p^{S, E}$ could be expressed in terms of coefficients which appear in the expansion of dipolemoment and potential energy (i.e. (3) and (4)).

$$
p^{S . E}=\sum_{j}\left(\beta_{j j}-\sum_{a} \frac{\alpha_{a} b_{a j j}}{\omega_{a}^{2}}\right) \frac{C_{j}}{\omega_{j}^{2}} .
$$

Here $C_{j}$ is the contribution of the $j$ th mode to the specific heat and is given by $\hbar \omega_{j}\left(\partial \bar{n}_{j} / \partial T\right), \bar{n}_{j}$ being the average occupition number of the phonons with energy $\hbar \omega_{j}$.

From the above expression, it could be shown that under Debye's approximation (which actually involves invoking some properties of $\beta_{j j}$ and $b_{a j j}$ ir. the long wavelength limit), the primary pyroelectric coefficient obeys $T^{3}$ law. But as has been rightly pointed 
out by Szigeti, in the case of complex polyatomic crystals, optic modes can have very low frequencies and hence the $T^{3}$ behaviour is observed only at very low temperatures. At this stage, it is also necessary to emphasize the role of both electrical and mechanical anharmonicity in primary pyroelectricity. Since the primary pyroelectric effect does not involve thermal expansion, for quite some time, it was regarded that only the electrical anharmonicity was responsible for primary pyroelectricity. It may be mentioned that thermal expansion is the result of mechanical anharmonicity. However, from the expression for primary pyroelectric coefficient, it is evident that the part played by mechanical anharmonicity cannot be neglected.

\section{Pyroelectric detector and the figure of merit of pyroelectric materials}

If the temperature change in a pyroelectric material is caused by the absorption of radiation, the observation of pyroelectric effect is equivalent to the detection of the radiation (Lecomte 1948). Basically, a pyroelectric detector consists of a thin pyroelectric crystal oriented with the electrode surface normal to its polarization vector. On absorbing the incident radiation the temperature of the pyroelectric material changes, which in turn changes the electric polarization. Thus pyroelectric material forms a capacitive element, the capacitance varying with temperature. The capacitor will deliver a current

$$
i=p A(\mathrm{~d} T / \mathrm{d} t),
$$

where $P$ is the pyroelectric coefficient, $A$ is the elcctrode surface area and $(\mathrm{d} T / \mathrm{d} t)$ is the rate of temperature change.

Since the pyroelectric current is proportional to the rate of temperature change, the device gives a steady output only if there is continuous variation in the temperature of the pyroelectric crystal due to modulation, pulsing or chopping of incident radiation. When the incident radiation is not modulated, pulsed or chopped. the device gives an output only till the time the pyroelectric crystal attains a steady temperature.

It must be noted that if the input radiation is slow compared to the thermal relaxation time of the crystal, the temperature essentially remains constant and the current response is low. For input frequencies higher than the thermal relaxation frequency full current response results because the absorbed energy goes into the heating of the crystal. The thermal relaxation frequency is given by

$$
f_{\text {thermal }}=G / 2 \pi H,
$$

where $G$ is the thermal conductance between the crystal and the surroundings and $H$ is the total heat capacity of the crystal. For a given crystal material and size, the thermal relaxation frequency is governed by conductance. Since the pyroelectric detector is made to respond to rate of change of temperature, it differs from other thermal detectcrs. The fact that the crystal does not have to come to thermal equilibrium as in the case of thermocouples and thermistors allows the pyroelectric detector to respond faster than other thermal detectors and still be sensitive to a wide spectrum of radiation wavelengths.

The performance of the pyroelectric detector is usually described by voltage responsivity (i.e. the pyroelectric voltage output per unit energy of incident radiation) and detectivity (i.e. the inverse of noise equivalent power (NEP) where NEP is defined as 
the incident energy required to produce a signal equal to that of detector noise). The voltage responsivity as well as the detectivity depend not only on the particular pyroelectric material but also on the characteristics of the amplifier employed for detecting the pyroelectric voltage. The detailed theory of pyroelectric detector has been discussed by several workers (Lang 1971; Liu 1978). It is sufficient for our purpose to know that the voltage responsivity is proportional to $p(\varepsilon c)^{-1}$ while the detectivity is proportional to $p\left(c(\varepsilon \tan \delta)^{1 / 2}\right)^{-1}$, where $p$ is the pyroelectric coefficient, $\varepsilon$ is the dielectric constant, $\tan \delta$ is the loss tangent and $c$ is the specific heat. Hence $p(\varepsilon c)^{-1}$ and $p\left(c(\varepsilon \tan \delta)^{1 / 2}\right)^{-1}$ could be regarded as the figures of merit of pyroelectric materials. Clearly, in the case of pyroelectric materials which are also ferroelectric the dielectric constant and the pyroelectric coefficient are strong functions of temperature and so is their figure of merit. It could be shown that the figure of merit is maximum at the temperature corresponding to the stability limit of the ferroelectric phase (Liu 1978).

\section{Pyroelectric materials}

An important component of pyroelectric detector technology pertains to the preparation of suitable pyroelectric materials. Since every pyroelectric material has its own advantages as well as disadvantages, a wide choice of pyroelectric materials is necessary not only for improving the detector performance but also to cater to specific applications of detectors. With the discovery of ferroelectricity in a large number of materials, the choice of pyroelectric materials has increased. In the beginning, the materials that were examined for pyroelectric detection included triglycine sulphate and barium titanate, which were among the few well-known ferroelectrics at that time. In recent years, a number of titanates, niobates, tantalates, zirconates, germanates and polymers have been studied for pyroelectric detection.

Apart from the study of new pyroelectric materials, another aspect of material technology pertains to the modification of material properties with a view to enhance the detector performance. Dielectric constant and dielectric loss are quite sensitive to dopants and also to radiation damage and hence can be monitored to some extent. Dopants also increase the coercive field and thus can be employed for obtaining single domain crystals, which are superior to multidomain ones. A number of mixed pyroelectric materials like strontium barium niobate, potassium tantalate niobate, lead zirconate titanate etc exhibit ferroelectricity over a wide range of composition of their constituents. In these crystals, it is possible to alter the curie temperature and pyroelectric coefficient by varying the composition. This property also has been made use of for improving the detector efficiency. Table 1 summarises the pyroelectric materials studied so far along with their figures of merit for voltage responsivity and detectivity.

The choice of the pyroelectric material is mainly determined by (a) its figure of merit, (b) the detector size, (c) availability and durability of the pyroelectric material, (d) environment in which the material has to operate, (e) the radiation levels to be detected, (f) the purpose for which the detector is employed, (g) the maximum ambient temperature of operation and the range over which stable operation is desired.

The importance of factors (b) and (c) in the choice of pyroelectric material does not need much of an explanation. It should be possible to grow large crystals of pyroelectric material and fabricate them into thin slices. The durability is also an important factor. 
Table 1. Figure of merit for various pyroelectric materials.

\begin{tabular}{|c|c|c|c|c|c|c|c|c|c|}
\hline Material & $\begin{array}{c}T\left({ }^{\circ} \mathrm{C}\right) \\
(1)\end{array}$ & $\begin{array}{c}\varepsilon \\
(2)\end{array}$ & $\begin{array}{c}p \\
\left(\times 10^{-8}\right) \\
(3)\end{array}$ & $\begin{array}{c}c \\
(4)\end{array}$ & $\begin{array}{c}s \\
(5)\end{array}$ & $\begin{array}{c}\rho \\
(6)\end{array}$ & $\begin{array}{c}\text { FM-R } \\
\left(\times 10^{-10}\right) \\
(7)\end{array}$ & $\begin{array}{c}\text { FM-D* } \\
\left(\times 10^{-4}\right) \\
(8)\end{array}$ & $\begin{array}{c}\text { Reference } \\
\text { (9) }\end{array}$ \\
\hline $\begin{array}{l}\text { TGS } \\
\left(T_{c}=49^{\circ} \mathrm{C}\right)\end{array}$ & $\begin{array}{r}0 \\
25 \\
40 \\
-25\end{array}$ & $\begin{array}{r}20 \\
35 \\
100 \\
20\end{array}$ & $\begin{array}{c}1 \cdot 3 \\
4.0 \\
12.0 \\
0.44\end{array}$ & $\begin{array}{l}2 \cdot 3 \\
2 \cdot 5 \\
2 \cdot 8 \\
-\end{array}$ & $\begin{array}{l}- \\
1.66 \\
-\end{array}$ & $\begin{array}{l}2.4 \times 10^{10} \\
1.7 \times 10^{10} \\
1.6 \times 10^{9} \\
1.1 \times 10^{10}\end{array}$ & $\begin{array}{l}2 \cdot 8 \\
4 \cdot 6 \\
4 \cdot 3 \\
0.96\end{array}$ & $\begin{array}{r}8 \cdot 8 \\
20 \cdot 9 \\
17 \cdot 1 \\
2 \cdot 0\end{array}$ & $\begin{array}{l}\text { Beerman } \\
(1975)\end{array}$ \\
\hline $\begin{array}{l}\text { DTGS } \\
\left(T_{\mathrm{c}}=61^{\circ} \mathrm{C}\right)\end{array}$ & $\begin{array}{r}0 \\
25 \\
50 \\
-25\end{array}$ & $\begin{array}{l}12 \\
18 \\
60 \\
11\end{array}$ & $\begin{array}{c}0.84 \\
2.7 \\
10.0 \\
0.42\end{array}$ & $\begin{array}{l}2 \cdot 4 \\
2 \cdot 5 \\
2 \cdot 8 \\
-\end{array}$ & $\begin{array}{l}- \\
1 \cdot 7 \\
-\end{array}$ & $\begin{array}{l}5.0 \times 10^{10} \\
5.0 \times 10^{10} \\
1.2 \times 10^{10} \\
1.8 \times 10^{10}\end{array}$ & $\begin{array}{l}2.9 \\
6.0 \\
6.0 \\
1.6\end{array}$ & $\begin{array}{r}7 \cdot 8 \\
24 \cdot 2 \\
39 \cdot 2 \\
2 \cdot 4\end{array}$ & $\begin{array}{l}\text { Beerman } \\
(1975)\end{array}$ \\
\hline $\begin{array}{l}\text { LATGS } \\
\left(T_{c}=49.5^{\circ} \mathrm{C}\right)\end{array}$ & 30 & 35 & 70 & 2.55 & 1.7 & -- & $7 \cdot 8$ & - & $\begin{array}{l}\text { Garn and } \\
\text { Sharp (1974) }\end{array}$ \\
\hline $\begin{array}{l}\text { DLATGS } \\
\begin{aligned}\left(T_{c}=49 \cdot 2^{\circ} \mathrm{C},\right. \\
\left.61 \cdot 2^{\circ} \mathrm{C}\right)\end{aligned}\end{array}$ & 25 & 22 & $2 \cdot 5$ & $2 \cdot 55$ & $1 \cdot 7$ & - & $4 \cdot 4$ & $\cdots$ & $\begin{array}{l}\text { Garn and } \\
\text { Sharp (1974) }\end{array}$ \\
\hline $\begin{array}{l}\text { TGFB } \\
\begin{aligned}\left(T_{c}=73 \cdot 8^{\circ} \mathrm{C},\right. \\
\quad\left(73^{\circ} \mathrm{C}\right)\end{aligned}\end{array}$ & 30 & 15 & $2 \cdot 1$ & 1.68 & 1.66 & - & $8 \cdot 3$ & - & $\begin{array}{l}\text { Garn and } \\
\text { Sharp (1974) }\end{array}$ \\
\hline $\begin{array}{l}\text { DTGFB } \\
\left(T_{c}=74 \cdot 5^{\circ} \mathrm{C}\right)\end{array}$ & 25 & 12 & $2 \cdot 5$ & 1.87 & $1 \cdot 7$ & - & $11 \cdot 1$ & - & $\begin{array}{l}\text { Garn and } \\
\text { Sharp (1974) }\end{array}$ \\
\hline $\begin{array}{l}\text { TGSE } \\
\left(T_{c}=22^{\circ} \mathrm{C}\right)\end{array}$ & 21 & 400 & 3.0 & 1.79 & $1 \cdot 7$ & - & 0.4 & - & $\begin{array}{l}\text { Garn and } \\
\text { Sharp (1974) }\end{array}$ \\
\hline $\begin{array}{l}\mathrm{BaTiO}_{3} \\
\left(T_{c}=135^{\circ} \mathrm{C}\right)\end{array}$ & $\begin{array}{r}25 \\
60 \\
100\end{array}$ & $\begin{array}{l}135 \\
200 \\
400\end{array}$ & $\begin{array}{r}1.9 \\
7.0 \\
20.0\end{array}$ & $\begin{array}{l}- \\
3 \cdot 0 \\
-\end{array}$ & $\begin{array}{l}- \\
6 \cdot 0 \\
-\end{array}$ & $\begin{array}{c}- \\
6.0 \times 10^{6} \\
-\end{array}$ & $\begin{array}{l}0.47 \\
1 \cdot 17 \\
1.67\end{array}$ & $\begin{array}{l}- \\
0.57 \\
-\end{array}$ & $\begin{array}{l}\text { Beerman } \\
(1975)\end{array}$ \\
\hline $\begin{array}{l}\mathrm{PbTiO}_{3} \\
\left(T_{c}=492^{\circ} \mathrm{C}\right)\end{array}$ & 25 & 142 & $2 \cdot 7$ & $3 \cdot 2$ & $7 \cdot 78$ & $5.3 \times 10^{8}$ & 0.59 & 1.90 & $\begin{array}{l}\text { Beerman } \\
(1975)\end{array}$ \\
\hline $\begin{array}{l}\mathrm{PbTiO}_{3} \\
\text { (Matsuohita) } \\
\left(T_{c}=470^{\circ} \mathrm{C}\right)\end{array}$ & 25 & 200 & 6 & $3 \cdot 2$ & $7 \cdot 78$ & - & 0.93 & - & \\
\hline $\begin{array}{l}\mathrm{LiNbO}_{3} \\
\left(T_{c}=1210^{\circ} \mathrm{C}\right)\end{array}$ & $\begin{array}{r}25 \\
100 \\
-25\end{array}$ & $\begin{array}{l}30 \\
31 \\
51\end{array}$ & $\begin{array}{l}0.4 \\
0.5 \\
2 \cdot 1\end{array}$ & $\begin{array}{l}-1.8 \\
3 \cdot 0\end{array}$ & $\begin{array}{l}- \\
4 \cdot 64 \\
-\end{array}$ & $\begin{array}{r}9.8 \times 10^{10} \\
6 \times 10^{10} \\
5.3 \times 10^{10}\end{array}$ & $\begin{array}{l}0.48 \\
0.58 \\
1.4\end{array}$ & $\begin{array}{r}- \\
4 \cdot 5 \\
16 \cdot 1\end{array}$ & $\begin{array}{l}\text { Beerman } \\
(1975)\end{array}$ \\
\hline $\begin{array}{l}\mathrm{LiTaO}_{3} \\
\left(T_{c}=618^{\circ} \mathrm{C}\right)\end{array}$ & $\begin{array}{r}0 \\
25 \\
50 \\
100\end{array}$ & $\begin{array}{l}52 \\
54 \\
56 \\
60\end{array}$ & $\begin{array}{l}2 \cdot 2 \\
2 \cdot 3 \\
2 \cdot 5 \\
2 \cdot 7\end{array}$ & $\begin{array}{l}3 \cdot 0 \\
3 \cdot 16 \\
3 \cdot 3 \\
3 \cdot 5\end{array}$ & $\begin{array}{l}- \\
7.45 \\
- \\
-\end{array}$ & $\begin{array}{l}4.4 \times 10^{10} \\
3.6 \times 10^{10} \\
2.9 \times 10^{10} \\
2.0 \times 10^{10}\end{array}$ & $\begin{array}{l}1.4 \\
1 \cdot 35 \\
1 \cdot 3 \\
1 \cdot 3\end{array}$ & $\begin{array}{l}15.4 \\
13.8 \\
12.9 \\
10.9\end{array}$ & $\begin{array}{l}\text { Beerman } \\
(1975)\end{array}$ \\
\hline $\begin{array}{l}\text { PZT4 } \\
\text { (clevite) } \\
\left(T_{c}=328^{\circ} \mathrm{C}\right)\end{array}$ & -25 & 1410 & $4 \cdot 6$ & 3.0 & - & $\begin{array}{l}3.2 \times 10^{8} \\
6.2 \times 10^{7}\end{array}$ & 0.109 & $1 \cdot 21$ & $\begin{array}{l}\text { Beerman } \\
(1975)\end{array}$ \\
\hline $\begin{array}{l}\text { PZTG-1306 } \\
\text { (Gulton) } \\
\left(T_{c}=290^{\circ} \mathrm{C}\right)\end{array}$ & $\begin{array}{r}0 \\
25 \\
50 \\
100\end{array}$ & $\begin{array}{l}1570 \\
1730 \\
1900 \\
2330\end{array}$ & $\begin{array}{l}4 \cdot 6 \\
4 \cdot 6 \\
4 \cdot 6 \\
4 \cdot 6\end{array}$ & $\begin{array}{l}- \\
3.0 \\
- \\
-\end{array}$ & $\begin{array}{l}- \\
7.6 \\
- \\
-\end{array}$ & $\begin{array}{l}5.9 \times 10^{7} \\
5.7 \times 10^{7} \\
5.4 \times 10^{7} \\
4.9 \times 10^{7}\end{array}$ & $\begin{array}{l}0.098 \\
0.089 \\
0.081 \\
0.066\end{array}$ & $\begin{array}{l}1 \cdot 18 \\
1 \cdot 16 \\
1 \cdot 13 \\
1 \cdot 07\end{array}$ & $\begin{array}{l}\text { Beerman } \\
(1975)\end{array}$ \\
\hline $\begin{array}{l}\text { PZT.HST }-41 \\
\left(T_{c}=270^{\circ} \mathrm{C}\right)\end{array}$ & $\begin{array}{r}25 \\
-25\end{array}$ & $\begin{array}{r}1800 \\
640\end{array}$ & $\begin{array}{l}2 \cdot 0 \\
4 \cdot 0\end{array}$ & $\begin{array}{l}3 \cdot 0 \\
-\end{array}$ & $\begin{array}{l}7 \cdot 6 \\
-\end{array}$ & $\begin{array}{l}4.5 \times 10^{7} \\
7.8 \times 10^{7}\end{array}$ & $\begin{array}{l}0.037 \\
0.24\end{array}$ & $\begin{array}{l}0.45 \\
1 \cdot 36\end{array}$ & $\begin{array}{l}\text { Beerman } \\
(1975)\end{array}$ \\
\hline $\begin{array}{l}\text { PZT } 5 \\
\left(T_{c}=365^{\circ} \mathrm{C}\right)\end{array}$ & - & 2100 & $4 \cdot 7$ & $3 \cdot 0$ & $7 \cdot 75$ & - & 0.075 & - & $\begin{array}{l}\text { Garn and } \\
\text { Sharp (1974) }\end{array}$ \\
\hline
\end{tabular}


Table 1. (contd)

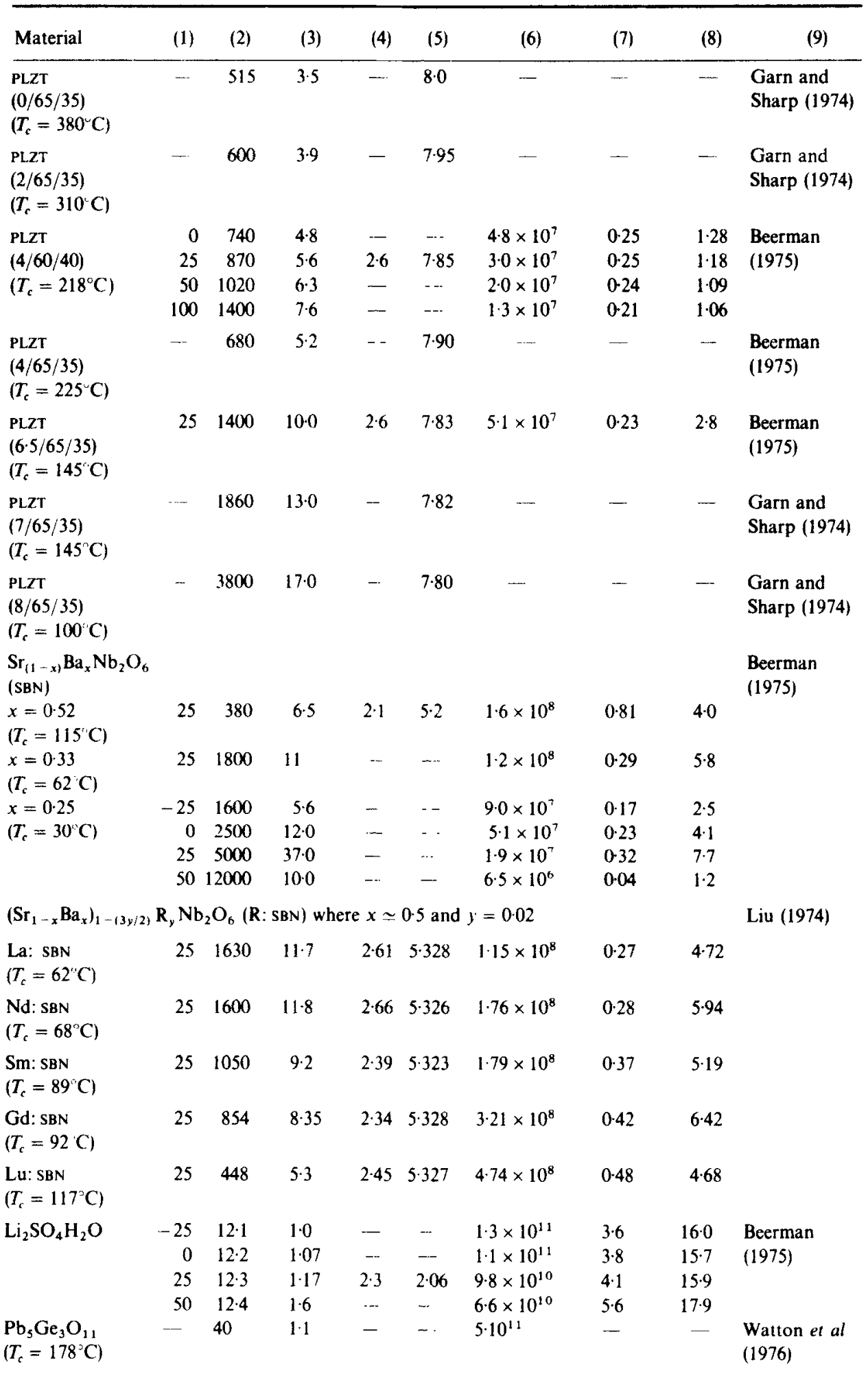


Table 1. (contd)

\begin{tabular}{|c|c|c|c|c|c|c|c|c|c|}
\hline Material & (1) & (2) & (3) & (4) & (5) & (6) & (7) & (8) & (9) \\
\hline $\begin{array}{l}\mathrm{Pb}_{4.75} \mathrm{Ba}_{0.25} \mathrm{Ge}_{3} \mathrm{O}_{1} \\
\left(T_{\mathrm{c}}=101^{\circ} \mathrm{C}\right)\end{array}$ & & 60 & $2 \cdot 0$ & - & - & $10^{14}$ & -- & - & $\begin{array}{l}\text { Watton et al } \\
(1976)\end{array}$ \\
\hline $\begin{array}{l}\mathrm{Pb}_{4 \cdot 70} \mathrm{Ba}_{0.3} \mathrm{Ge}_{3} \mathrm{O}_{11} \\
\left(T_{\mathrm{c}}=70^{\circ} \mathrm{C}\right)\end{array}$ & & 81 & 32 & - & - & $10^{14}$ & - & - & $\begin{array}{l}\text { Watton et al } \\
\text { (1976) }\end{array}$ \\
\hline $\begin{array}{l}\mathrm{Na} \mathrm{NO}_{2} \\
\left(T_{\mathrm{c}}=163^{\circ} \mathrm{C}\right)\end{array}$ & 25 & 7.4 & 0.5 & $2 \cdot 1$ & $2 \cdot 2$ & -- & $3 \cdot 2$ & - & $\begin{array}{l}\text { Garn and } \\
\text { Sharp (1974) }\end{array}$ \\
\hline $\begin{array}{l}\text { Polyvinyl- } \\
\text { chloride (PVC) }\end{array}$ & - & $5 \cdot 33$ & 0.01 & - & - & - & - & - & $\begin{array}{l}\text { Garn and } \\
\text { Sharp (1974) }\end{array}$ \\
\hline $\begin{array}{l}\text { Polyvinyl } \\
\text { fluoride (PVF) }\end{array}$ & - & $5 \cdot 0$ & $\begin{array}{l}0.10 \\
0.18\end{array}$ & $2 \cdot 3$ & 1.38 & - & 0.87 & - & $\begin{array}{l}\text { Garn and } \\
\text { Sharp (1974) }\end{array}$ \\
\hline $\begin{array}{l}\text { Polyvinylidene } \\
\text { fluoride }\left(\mathrm{PVF}_{2}\right)\end{array}$ & - & $11 \cdot 0$ & $0-30$ & $2 \cdot 4$ & 1.76 & - & - & - & $\begin{array}{l}\text { Garn and } \\
\text { Sharp (1974) }\end{array}$ \\
\hline $\begin{array}{l}\text { Polyacryl- } \\
\text { nitrile (PAN) }\end{array}$ & - & $7 \cdot 7$ & $\begin{array}{c}0.005 \\
0.01\end{array}$ & - & - & - & - & - & $\begin{array}{l}\text { Garn and } \\
\text { Sharp (1974) }\end{array}$ \\
\hline $\begin{array}{l}\text { Poly (4-nitro- } \\
\text { styrene) } \\
\text { atactic }\end{array}$ & - & 6.2 & 0.006 & -- & - & - & - & - & $\begin{array}{l}\text { Garn and } \\
\text { Sharp (1974) }\end{array}$ \\
\hline $\begin{array}{l}\text { Polyacry- } \\
\text { lamide (PAA) }\end{array}$ & - & - & 0.01 & - & - & -- & - & - & $\begin{array}{l}\text { Garn and } \\
\text { Sharp (1974) }\end{array}$ \\
\hline
\end{tabular}

(1) $T\left({ }^{\circ} \mathrm{C}\right)$ : Temperature in ${ }^{\circ} \mathrm{C}$ at which measurements are made; (2) $\varepsilon$ : Dielectric constant;

(3) $p$ : Pyroelectric coefficient in Coul $/ \mathrm{cm}^{2} / \mathrm{K}^{\circ}$; (4) $\mathrm{c}$ : Volume specific heat in $\mathrm{J} / \mathrm{cm}^{3} / \mathrm{K}^{\circ}$;

(5) s: Density in $\mathrm{g} / \mathrm{cm}^{3}$; (6) $\rho$ : AC resistivity in ohm-cm; (7) FM-R: Figure of merit for voltage responsivity given by $p(\varepsilon c)^{-1} ;(8)$ FM-D*: Figure of merit for detectivity given by $p \rho^{1 / 2} c^{-1}$;

(9) Ref.: Reference

Table 1 clearly indicates that TGS and $\mathrm{Li}_{2} \mathrm{SO}_{4} \cdot \mathrm{H}_{2} \mathrm{O}$ are good materials for pyroelectric detection. But the main problem is their hygroscopic nature, which restricts the operating conditions. Therefore $\mathrm{LiTaO}_{3}$ is generally preferred. The problem is rather crucial for vidicon applications, where the material ought to be not only physically and chemically stable in the temperature and pressure conditions of the tube but also have low thermal diffusivity, to obtain good spatial resolution. That is why $\mathrm{PVF}_{2}$ is gaining much attention for vidicon applications on account of its low thermal diffusivity as compared to that of $\mathrm{TGS}$ and $\mathrm{LiTaO}_{3}$, and also the ease with which thin target materials can be prepared.

Similarly for application in laser optics, the choice of the material is governed by its vulnarability to radiation damage. Invariably crystals like TGS are not employed. Materials with high curie temperature are found to be resistant to radiation damage. The phenomenon of surface damage by laser pulses is not very well understood. Thus the $\mathrm{LiTaO}_{3}$ detector is found to be satisfactory in the $1 \mathrm{~mW}-3 \mathrm{~W}$ average power levels from $10.6 \mu \mathrm{m} \mathrm{C.W} \mathrm{CO}$ laser, but is damaged by a single $1 / 3 \mathrm{~J}$ pulse with a duration of $200 \mathrm{msec}$. But a PzTG 1306 detector is not damaged even after fifty pulses. It has been observed that polycrystalline ceramic pyroelectric materials are more resistant to radiation damage than single crystals. Strontium barium niobates are another class of pyroelectric materials which are extensively employed in laser detection.

The temperature at which the detector has to be operated also determines the choice of the pyroelectric material. For better sensitivity of the detector, the curie temperature 
must be as close to that of the operating temperature (in such a case, it also becomes necessary to take special care to avoid depoling in the material). In this sense, it is useful to have pyroelectric materials whose curie temperature could be changed by changing the composition, doping etc. This accounts for the interest in materials like SBN, KTN, $\mathrm{Pb}_{5} \mathrm{Ge}_{3} \mathrm{O}_{11}$, TGS-TGSE and PLZT ceramics. Of late ceramic-plastic composites and improper ferroelectrics are found to have good potential of becoming efficient pyroelectric materials. (Harrison and Liu 1980; Newnham et al 1980; Shaulov et al 1980). The PZT-plastic composite has a figure of merit six times more than that of PZT. The absence of dielectric divergence in improper ferroelectrics makes it possible to have a high figure of merit. The rare earth molybdates, propionates and boracites are found to be superior to TGS.

\section{Acknowledgement}

The Author is thankful to Prof R Vijayaraghavan and Dr M S Multani for their kind interest.

\section{References}

Beerman H P 1975 Infrared Phys. 15225

Born M 1945 Rev. Mod. Phys. 17245

Born M and Huang K 1954 Dynamical theory of crystal lattices (Oxford: Clarendon Press)

Garn L E and Sharp E J 1974 IEEE Trans. Parts Hybrids Package PHP10 208

Harrison W B and Liu S T 1980 Ferroelectrics 27125

Lang S B 1971 Source book on pyroelectricity (New York: Gordon and Breach)

Lecomte J 1948 Proc. Indian Acad. Sci. A28 339

Liu S T 1974 J. Electr. Mater. 391

Liu S T 1978 Proc. IEEE $\overline{6} 6 \overline{14}$

Newnham R E, Skinner D P, Klicker K A, Bhalia A S, Hardimar B and Gururaja T R 1980 Ferroelectrics 2749

Nye J F 1962 Physical properties of crystals (Oxford: Clarendon Press)

Shaulov A, Smith W A, Loiacano G M, Bell M T and Tauo Y H 1980 Ferroelectrics 27117

Szigeti B 1975 Phys. Rev. Lett. 351532

Szigeti B 1976 Phys. Ret. Lett. 37792

Watton R, Smith C and Jones G R 1976 Ferroelectrics 14719 